\title{
THE POSITIVE EFFECTS ON MENTAL HEALTH OF VISITING BOTANIC GARDENS
}

\author{
Sophia Shaw ${ }^{l}$
}

\begin{abstract}
This paper continues the Guest Essay theme on the positive contribution that experiences in gardens and nature can make to people. It draws on her own and others' personal experiences, particularly in Chicago Botanic Garden, to demonstrate that time spent in a garden, whether as a casual visitor or as a participant in specialised horticulture therapy and education programmes, can improve mental health and physical well-being and that this is to the benefit of individuals and society as a whole. The paper finishes with a comment on the value of the scientific work carried out by botanic gardens and how this also contributes positively to mental health by empowering people to do something constructive about the ecological challenges facing society.
\end{abstract}

\section{INTRODUCTION}

In my Guest Essay I described how growing a thriving garden and balancing the mind requires that we adhere to the same principles: patience, beauty, science, a desire to learn from and give to each other, hard work, respect and faith. In this paper I continue this theme by describing the value that visiting botanic gardens and taking part in the events held there can have on the mental health of individuals.

\section{VISITING BOTANIC GARDENS}

The positive effects of gardening also come from walking through botanic gardens, arboreta and conservatories. My first memory of a public garden is from the Lincoln Park Conservatory in Chicago when I was seven or eight years old. The warmth, and particularly the orchids at the front door, calmed and comforted me. I would press my nose into the purple Cattleya and breathe in deeply. Those were very difficult times for my family, with much anger, loneliness, illness, uncertainty and worry. The Lincoln Park Conservatory's orchids, as well as their spring flower show - bursting with colourful azaleas and fragrant hyacinths, gardenias and daffodils - gave me so much pleasure and reassurance that writing about this today, 40 years later, my heart breaks at the sadness that little girl felt, but also swells with appreciation for the horticulturists who brought her a bit of peace each spring. I feel a great sense of joy in knowing that the Chicago Botanic Garden Orchid Show and other horticultural displays deliver this same kind of

1. Sophia Shaw is President and CEO of Chicago Botanic Garden. Address: 1000 Lake Cook Road, Glencoe, IL 60022, USA.

Email: sophiashaw@icloud.com 
healing to countless others. I am also thankful that through my role, I can help others use flowers and gardens to find comfort and a way out of their own dark moments.

In all four seasons, even in below-freezing temperatures and snow, the Chicago Botanic Garden has hundreds of people walking our paths. While some people only visit occasionally, many members walk or drive through our gates every day. Why? While many visit for physical fitness, many also describe the mental relief they achieve. One woman, who most often arrives in late afternoon during the summer, confided to a member of our Garden's staff, "This is where I come to get centred." One Garden volunteer with multiple sclerosis calls the Garden his "own, personal Eden; a place when all that is wrong with the world disappears". On the tenth anniversary of the September 11 attacks on the World Trade Centre, my younger son and I walked in silence around the Garden's Great Basin, listening to our carillon toll 2,977 times, each chime representing a life. And while my son, who was not yet born in 2001, did not personally know the pain of that day, he was able to share with everyone who gathered at the Garden that morning a moment of reflection and healing in a beautiful and safe place. At a botanic garden, the healing power of nature is evident every day, calming the spirit and nurturing the body and mind.

The healing power of nature is not simply anecdotal. According to experts studying the connection between nature and well-being, the 'nurture of nature' is experienced when we immerse ourselves in natural surroundings. A number of international researchers have published studies pointing to a variety of health benefits from exposure to nature. Japanese researchers at Tokyo's Nippon Medical School, for example, found that practising shinrin-yoku, or 'forest bathing' - a consciously reflective walk through a forest - increased production of important white cells in the human immune system. ${ }^{2}$ Another study from the United Kingdom demonstrated that even a single episode of walking or running outdoors in natural environments created greater feelings of revitalisation and decreased tension than the same activity performed indoors. Scientists at the University of Michigan, in collaboration with the Yale School of Forestry, are working to document these benefits, as is the American Public Health Association, in a project entitled 'Improving Health and Wellness through Access to Nature'. ${ }^{3}$ These efforts, and those of the therapists at the Chicago Botanic Garden and scientists at Northwestern University, focus closely on helping people form closer relationships with nature so they can enjoy the physical, emotional and intellectual benefits that result from this interaction. These academic and 'on-the-ground' experts will help catalyse badly needed research on the health benefits of nature that can, in turn, support better planning, policymaking and design for people and places.

Our Garden's volunteer corps - now exceeding 2,000 people - provides individuals from many backgrounds and stages of life with the opportunity to come together to do

2. More information including links to numerous articles and studies may be found on the website of the International Society of Nature and Forest Medicine at http://www.infom.org/paperandbooks

3. See http://apha.org/policies-and-advocacy/public-health-policy-statements/policy-database/2014/07/08/09/18/improvinghealth-and-wellness-through-access-to-nature 
important work and to reap the benefits of making new friends. Many people often start volunteering after a significant change in their life - at the end of a professional career, when grown children have left the house or after a death of a spouse. One volunteer who lost her husband to cancer decided to spend time in the Garden and sought out repetitive, meditative tasks as part of her grieving. She enjoys her hours and often fondly recalls times spent with her husband as she works to deadhead flowers or pull weeds. Botanic gardens are becoming viewed as 'wellness' centres in diverse cultures and communities worldwide, because they increasingly provide a place of refuge for mental and physical healing - for people of all ages, backgrounds and abilities.

After enjoying the Chicago Botanic Garden over many seasons, many people choose to honour loved ones there as a way to remember someone who passed away or to recognise a moment of celebration. For example, a Garden staff member recently lost her friend, Marielle, who died at age 47 from liver cancer. This winter, Marielle's mother dedicated a flowering crab apple at the Garden in memory of her daughter, and she and her daughter's friend look forward to enjoying its blossoms each spring. This tribute is a reminder of the lives that botanic gardens touch and the opportunities that we create for families to heal, often without even knowing we do.

\section{HEALING, EDUCATION AND SCIENCE PROGRAMMES OF BOTANIC GARDENS}

Today's botanic gardens offer so much more than simply safe havens for reflection and introspection. I know that in recent years when my mental health has been most fragile and when I have felt at my most vulnerable, I have been consoled not only by walking through botanic gardens but by enrolling in garden classes, investing myself in the plant conservation and educational efforts of a botanic garden, eating the harvest resulting from urban agriculture programmes and seeing the social and community bonds formed at botanic gardens throughout the world.

Public garden cafés have become community centres - places to gather with friends, visit alone or meet strangers for the first time. Birdwatching and photography clubs meet at public gardens to practise their passion and compare notes. Garden exhibitions, fairs, festivals, concerts, yoga and tai-chi classes, walking groups, flower shows and festivals also bring people together, generating joy and fun, reducing stress and promoting healing by building a broader definition of community. Garden programmes bring people of different cultures and faiths together on common ground, and early on during my time at the Chicago Botanic Garden, I had a first-hand experience in this regard when I walked by our visitor centre as two school buses were unloading. From one bus flowed smiling boys wearing traditional Hasidic Jewish clothing; from the other bounced Muslim girls, conservatively covered. The interfaith, cross-cultural nature of a botanic garden visit makes me feel good - it makes me feel more connected to the common concerns, hopes and dreams of all people in the world.

My responses to gardens are consistent with the mental health benefits they have afforded people over many millennia, but there are also specific points in history 
during which gardens and gardening came to be understood in a prescriptive sense by the health professions. This practice continues to grow today. The use of horticultural therapy - similar to art and music therapy - in nursing homes and long-term care facilities to help war veterans recover from psychological and physical wounds dates back to the 19th century, and was a noted rehabilitation technique following both World Wars. According to Sharon Simson and Martha C. Straus in Horticulture as Therapy: Principles and Practice (2003), it was Dr Benjamin Rush, a signatory of the Declaration of Independence as well as one of the early founders of American psychiatry, who first documented the positive effect working in the garden had on individuals with mental illness. In an article in Science, Roger S. Ulrich (1984) presented evidence that showed hospital patients improved their health when they could observe nature. Earl Bakken, co-inventor of the cardiac pacemaker and founder of Medtronic, one of the world's leading medical technology companies, believes so strongly in nature-inspired therapies and the power of positive mental health to aid in physical recovery, that he became the benefactor of the North Hawaii Community Hospital, a unique medical centre that emphasises the importance of its garden campus in healing the mind and body. However, while the benefits of gardens on the mental health of patients are broadly accepted, more quantitative data on the physical, emotional and even intellectual benefits that interaction with gardening and nature affords is needed. It is my hope that through symposia such as 'Nature, Culture, and Human Health' (Chicago Botanic Garden, 2014) and other initiatives, a broader base of evidence will be established to support the more widespread use of horticultural therapy throughout the medical community.

Even without a wealth of conclusive clinical studies, for decades botanic gardens have been practising formal therapeutic horticulture programmes that complement traditional healthcare. The Chicago Botanic Garden serves health and social organisations and schools with activities tailored to each population's ages, abilities and interests. Examples include the NorthShore University HealthSystem's stroke support and Cancer Wellness Centre, and the Veterans Project, designed in partnership with Thresholds, a mental health agency with a mission to transform the lives of people struggling with mental illness. The Veterans Project supports veterans with Post-Traumatic Stress Disorder (PTSD) and other emotional challenges by using the healing power of nature and plants at a series of retreats in the Buehler Enabling Garden at the Chicago Botanic Garden. Participants engage in a variety of activities, from keeping a journal to planting and harvesting projects to creating memorial garden stones. The programme serves veterans from all branches of the military services, focusing on those returning from recent conflicts. The sessions are designed to ease reintegration and provide a peaceful environment for personal expression, reflection and sharing experiences. During one of his visits, Iraq War veteran Fernando Valles described the Garden as a "safe" space for the veterans. He went on to say, "It's very important to have a safe space because when we were in other places of the world defending this country, we never felt safe."

The Chicago Botanic Garden also provides horticultural therapy activities in three local Veterans' Affairs (VA) hospitals. Garden staff are consulting and training VA staff 
and clients on building and maintaining edible and display gardens and programming for new VA 'Green House' residences, group homes for older veterans. The horticultural therapist in the outpatient unit serves substance-abuse programmes and an intensive daily outpatient mental health treatment programme, including sessions for women veterans who were victims of sexual assault and for recent combat veterans suffering from PTSD. An activity designed for older veterans from World War II and the Vietnam and Korean Wars was piloted with the outpatient unit. The horticultural therapist connected planting activities with stories about plants that soldiers used during active duty for health and healing. For example, the older veterans discussed mint and its use for headache and insomnia, and eucalyptus and the positive effects it has on colds and coughs. They also filled individual tea bags with sweet mint for the younger men to take home. This medicinal plant activity elicited memories, stories and, for some, anger - all of which were discussed within the context of the therapeutic horticulture session. Participants benefit between sessions by caring for plants they have brought home. Maurice Person, a Vietnam veteran, shared his experience:

\section{I, Maurice Person, is [sic] very happy to have the horticultural therapy services here at the Jesse Brown VA Hospital. The Botanical Garden is very vital to my recovery and to the VA hospital, it gives us the opportunity to [learn] how to grow plants, herbs ... that help us to be at peace and joy and be creative which [helps] us in recovery make life saving changes and find new way to enjoy life and become productive.}

In addition to working with veterans, botanic gardens also work with hospice and palliative care centres to design gardens and console patients' grieving family members. The family of a hospice patient brought her to the Chicago Botanic Garden in the hope of breaking through her profound depression. She reached out to pluck some chives and nibble on them. Within 20 minutes, she was correcting her family's misidentification of plants and requesting to be wheeled to specific locations in the Garden. When she died several weeks later, her family sent a copy of her funeral programme. On the front it featured a photo of her in the Garden. One of my most profound moments in this regard was being present when a Chicago Botanic Garden donor, Tony Grunsfeld, said goodbye to his family and friends at the ground-breaking of the Grunsfeld Growing Garden. Garden staff had learned that Tony was ill, so we decided to put the shovel in the ground for a new project several months before we had planned. Although weak, Tony stood with his whole family - sister, children and grandchildren - and in a very strong voice told them how much he had appreciated their love and how proud he was of them. Seventeen days later, after a rapid decline, Tony died. But he lives on in those of us who were present that day and in the Garden enjoyed by thousands of children each year that he and his family made possible. There are hundreds of stories like this one; just as many new mothers and fathers bring their newborn babies to the Garden, so is the Garden the last place many people visit 
before they die - a place of comfort, where life is affirmed in a general sense even as it fades for an individual.

Gardening has also demonstrated positive effects for children with sensory and motor disabilities, learning and behavioural challenges, attention deficit/hyperactivity disorder (ADHD) and those at all stages along the autism spectrum (Kuo \& Taylor, 2004; Jaffe, 2010). On a sensory tour of the Chicago Botanic Garden, students from Hamilton Elementary School were intrigued by a flower that smelled like a combination of pineapple and coconut. Initially timid, these young children abandoned their fears and engaged with the Garden, running from flower to flower to smell and playing in the fountains. Special education students from Evanston Township High School delighted in harvesting herbs and making and feasting on a herb dip. The Jane A. Neil School, a public school in the Chatham neighbourhood on Chicago's South Side, brought their seventh graders to learn about enabling and sensory gardens; their class subsequently began designing a school garden to be accessible to the approximately 50 per cent of the student population with special needs. Teachers from a school with students who have severe multiple disabilities tell us they bring their students for a horticultural therapy session every summer because the nonverbal children respond actively to the environment and those with tremors tend to relax.

My friend Jeanne Nolan, author of From the Ground Up: A Food-Grower's Education in Life, Love and the Movement That's Changing the Nation (2003) and the person who originally encouraged me to write an essay drawn from my personal experiences, works with children at the Edible Garden at the Lincoln Park Zoo in Chicago. She recounts the following in her compelling book:

On Saturday, a young boy and his father noticed me working in the garden and stopped by on their way to see the farm animals. Some of the early crops were ready to be harvested, and Tommy, a city kid, thrust his hands into the dirt and worked happily ... He fell into a hypnotic rhythm snapping beans off their vines, pulling up one weed and then the next ... On their fourth visit, Tommy showed up wearing fist-sized headphones that looked too big for his five-yearold head. His father explained that they'd just come out of occupational therapy for Tommy's early stage attention deficit/hyperactivity disorder. I was stunned - Tommy had been by far the most attentive and engaged visitor to the garden and he seemed to me anything but distracted. "It's a surprise to me, too," his father said. "He's a handful at home and at school, but there's something about gardening that seems to help him."

We also see the mental healing effect of gardens on high-achieving youth from urban neighbourhoods in Chicago through the Chicago Botanic Garden's Science Career Continuum, a programme designed to engage Chicago public schools students who may be the first in their family to attend college, and to connect with students in an immersive way with plant-based learning led by Garden professionals over an extended period of 
time. The goal is that they will go to college and graduate school, major in a science field and increase the representation of African-Americans and Hispanics in science-related fields, particularly biology and plant science.

The Science Career Continuum has been very successful, and we have learned over the years that being at and working in both native habitats and designed gardens such as those at the Chicago Botanic Garden can be an essential feature of learning and development for young people. Participants are selected for the Continuum at age thirteen or fourteen, and they spend four or five years returning to the Garden for an intensive eight-week programme every summer. The impact on these students of being in nature - guided by caring, attentive adults in a natural environment - has been profound. The transformation becomes evident in a matter of a few weeks. The students soften, start talking more and relax. They are allowed to do what the educator John Dewey always said was essential: connect learning through their hands, to their hearts, to their heads. They also begin having deeper and more reflective thoughts about life in general, about society, about significant questions that transcend their immediate personal concerns. In light of the Continuum's impressive results and the impact of many other similar experiences, I don't believe there remains any doubt that botanic gardens' nurturing, relaxing and inspiring atmospheres are good for helping people think both bigger and deeper thoughts.

The same has been shown to be true for people enrolled in native-plant and foodgrowing programmes operated in partnership with prisons, schools and healthcare clinics. For example, the Sustainability in Prisons Project of the Washington State Department of Corrections and the Evergreen State College in Olympia, Washington, works with incarcerated youth and adults to grow native plants for habitat restoration. Nalini Nadkarni $\mathrm{PhD}$, the programme's founder and a professor of environmental studies at Evergreen State, is researching the effects of viewing nature imagery on the sense of well-being in prisoners. Inmates involved in programmes where they care for living things report increased calmness and lower blood pressure. One prisoner enrolled in a plant nursery programme in Oregon stated, "I can't think of better karma than planting trees and prairie restoration."

The Chicago Botanic Garden's Windy City Harvest programme is an urban agriculture education and jobs-training initiative for urban youth, formerly incarcerated youth and adults, and others with significant barriers to employment. Working in urban sites often circumscribed by danger and hardscape, participants use gardening to turn these locations into 'safe spaces'. Certainly, safe spaces can be created in many environments, but having one made for growing plants connects people with a unique opportunity for personal growth, renewal and hope. When we can bring together the benefits of urban farming programmes with local health organisations, as the Chicago Botanic Garden has done with PCC Community Wellness Centre on Chicago's West Side, the beneficial effects are amplified. Formalising the relationship between botanic gardens and a broad array of other institutions - hospitals, doctors and clinics, as well as schools, prisons and alternative correctional sentencing programmes - helps build a 
holistic community of prevention and care. The result is improved mental and physical health for patients, students and inmates, inside and outside physicians' offices, at all stages of life.

Botanic gardens also lead the world's efforts in plant science. Plant conservation biology science programmes offer international leadership in healing local ecosystems, training conservation practitioners, stewards and land managers, and finding ways to mitigate and adapt to the effects of climate change, invasive species and fragmented natural habitat. Plant scientists, many of whom work at botanic gardens, conserve and heal nature's delicate ecosystems that depend on the plant and fungi kingdoms for survival. Garden scientists from around the globe, united by an association with Botanic Garden Conservation International (BGCI), explore questions about the ecology and evolution of native perennial plants. These scientists use fieldwork, together with both basic and sophisticated laboratory techniques, to investigate how we can maintain healthy ecosystems in the future. We engage volunteers and citizen scientists in monitoring plant and animal species, and we develop strategies and advocate for policies that protect and conserve. Since ancient Mesopotamia, gardens have banked seeds for conservation and food security. Today the Millennium Seed Bank project partners have collected close to two billion seeds from more than 34,000 species of plants from around the globe. Like a fertility clinic that preserves sperm and eggs while developing techniques for enhancing human reproduction, we store seeds in anticipation of restoring plant-based ecosystems when they are destroyed. In other words, the goal of many botanic garden science programmes, most particularly ours in Chicago, is to heal ecosystems in a such a way a doctor would - helping a patient develop a routine for general fitness, determining a diagnosis if the patient becomes sick, discovering and applying treatments, and monitoring the response.

\section{CONCLUSION}

How does all this relate to helping build strong mental health? Simply stated, when we help comfort or heal others, we comfort and heal ourselves. When we can save a plant, save a habitat or help a person, we experience a strong surge of positive energy and optimism. Seeds of many species can last 200 years or more when properly stored. Knowing that my great-grandchildren might be able to benefit from the seeds banked by the Chicago Botanic Garden and help restore healthy habitats calms me today and makes me optimistic that there will be options for the future. I rejoice in the reciprocity that exists here - I help support the plant that is pollinated by a bee, whose honey flows more bountifully, that provides delight for man and beast, and I am happy. My happiness makes me want to save more plants, and so on ... Gardens are literally healing people while healing ecosystems because all life on earth depends on plants and healthy habitats, and we are figuratively healing people as well - enhancing mental health. 


\section{REFERENCES}

CHICAGO BOTANIC GARDEN (2014). Nature, Culture, and Human Health Symposium Proceedings. Available online: www.chicagobotanic.org/nurture-nature (accessed June 2015).

JAFFE, E. (2010). This side of paradise: discovering why the human mind needs nature. Association for Psychological Science Observer 23:5 (May/June 2010). Available online: www.psychologicalscience.org/index.php/publications/observer/2010/may-june-10/thisside-of-paradise.html (accessed June 2015).

KUO, F.E. \& FABER TAYLOR, A. (2004). A potential natural treatment for Attention-Deficit/ Hyperactivity Disorder. American Journal of Public Health 94(9): 1580-1586.

NOLAN, J. (2013). From the Ground Up: A Food Grower's Education in Life, Love, and the Movement That's Changing the Nation. Spiegel and Grau, New York, pp. 126-127.

SIMSON, S. \& STRAUS, M.C. (2003). Horticulture as Therapy: Principles and Practice. Routledge, London and New York.

ULRICH, R.S. (1984). View through a window may influence recovery from surgery. Science 224(4647): 420-421. 
